\title{
(2) OPEN ACCESS \\ From the origin of NASH to the future of metabolic fatty liver disease
}

\author{
Andreas Geier (1) , ${ }^{1}$ Dina Tiniakos, ${ }^{2}$ Helmut Denk, ${ }^{3}$ Michael Trauner (i) ${ }^{4}$
}

'Division of Hepatology, Department of Medicine II, University Hospital Würzburg, Würzburg, Bayern, Germany ${ }^{2}$ Department of Pathology, Aretaieion Hospital, Medical School, National \& Kapodistrian University of Athens, Athens, Greece \& Translational \& Clinical Research Institute; Faculty of Medical Sciences, Newcastle University, Newcastle upon Tyne, UK

${ }^{3}$ Institute of Pathology, Medical University of Graz, Graz,

Steiermark, Austria

${ }^{4}$ Division of Gastroenterology and Hepatology, Department of Medicine III, Medical University of Vienna, Wien, Wien, Austria

\section{Correspondence to} Professor Andreas Geier Medical Center, Division of Hepatology, University of Würzburg, Wurzburg, Bayern, Germany;

Geier_A2@medizin.uniwuerzburg.de

Received 28 September 2020 Revised 13 January 2021 Accepted 5 February 2021 Published Online First 25 February 2021

\section{ABSTRACT}

Non-alcoholic fatty liver disease (NAFLD) has become the most common cause of chronic liver disease worldwide. Understanding the pathological and molecular hallmarks from its first description to definitions of disease entities, classifications and molecular phenotypes is crucial for both appropriate clinical management and research in this complex disease. We provide an overview through almost two hundred years of clinical research from the beginnings as a nebulous disease entity of unknown origin in the 19th century to the most frequent and vigorously investigated liver disease today. The clinical discrimination between alcohol-related liver disease and NAFLD was uncommon until the 1950s and likely contributed to the late acceptance of NAFLD as a metabolic disease entity for long time. Although the term 'fatty liver hepatitis' first appeared in 1962, it was in 1980 that the term 'non-alcoholic steatohepatitis' (NASH) was coined and the histopathological hallmarks that are still valid today were defined. The $2005 \mathrm{NASH}$ Clinical Research Network scoring was the first globally accepted grading and staging system for the full spectrum of NAFLD and is still used to semiquantify main histological features. In 2021, liver biopsy remains the only diagnostic procedure that can reliably assess the presence of NASH and early fibrosis but increasing efforts are made towards non-invasive testing and molecular classification of NAFLD subtypes.

\section{INTRODUCTION}

Non-alcoholic fatty liver disease (NAFLD) comprises a wide spectrum of liver damage, ranging from NAFL (simple steatosis; NAFL), to nonalcoholic steatohepatitis (NASH) with inflammation and hepatocyte injury to advanced fibrosis and cirrhosis. ${ }^{1}$ Although NAFLD histopathology resembles that of alcohol-related liver disease (ALD), the clinical background is different. NAFLD is regarded as one component of the metabolic syndrome, including obesity, insulin resistance or type 2 diabetes mellitus, hypertension and dyslipidaemia. A 'multiple parallel hits' hypothesis describes the pathogenesis of this complex disease from simple steatosis to steatohepatitis. ${ }^{2}$ NAFLD affects $10 \%-24 \%$ of the general population worldwide and is the most common cause of chronic liver disease. $^{4}$

The worldwide number of obese patients tripled from 1975 to $2018 .^{5}$ The introduction of industrialised food rich in high fructose corn syrup (HFCS) in the late 1960s coincided with the increase in the incidence of obesity, diabetes and metabolic syndrome. Bray et al ${ }^{6}$ first hypothesised that HFCS

\section{Key message}

- Obesity has been noticed in antiquity but fatty liver as a disease entity was unknown until the early 19th century.

- A causal relationship between hepatic fat accumulation and the development of fibrosis has been observed in 1839 followed by the microscopic finding that 'fatty degeneration' develops close to inflammatory deposits and scarring.

- The clinical discrimination between alcoholrelated and non-alcoholic fatty liver disease (NAFLD) was uncommon until the 1950s. After the introduction of percutaneous biopsies, the association of fatty liver disease with diabetes mellitus became increasingly apparent.

- The term 'fatty liver hepatitis' first appeared in 1962 in the German literature while the term 'non-alcoholic steatohepatitis' (NASH) was coined in 1980, defined by the histopathological hallmarks of steatosis, lobular inflammation, liver cell damage with ballooning and, eventually, appearance of Mallory-Denk bodies.

- Grading and staging systems for steatosis and fibrosis emerged in the 1950s but the NASH Clinical Research Network score in 2005 was the first globally accepted histological scoring system that addressed the full spectrum of NAFLD.

- Liver biopsy still remains the only diagnostic procedure that can reliably assess the presence of NASH and early fibrosis but increasing efforts are made towards non-invasive testing and molecular classification of disease subtypes.

may be directly associated with obesity. ${ }^{6}$ However, carefully controlled long-term studies are still required to substantiate the aetiological role of HFCS in metabolic syndrome-related diseases, such as NAFLD. ${ }^{7}$ Given the sheer frequency of patients with obesity, metabolic syndrome and NAFLD, it is remarkable that this disease entity has been overlooked by most clinicians for a long time, except for few pioneers, mostly pathologists, who first described the clinical and pathological characteristics more than 150 years ago. Even as recently as 30 years ago, NASH was familiar only to a small group of experts and the term did not exist in the medical vocabulary until 1980 . Today, the lack of awareness of NAFLD by the clinical community has contributed to a lack of NASH-specific drugs and reliable 

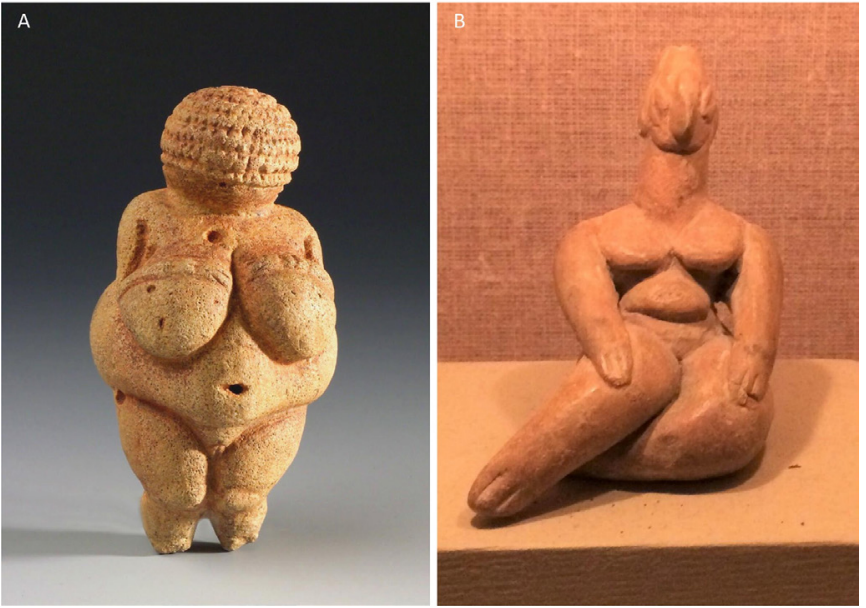

Figure 1 Venus figurines of obese women. (A) Venus of Willendorf. The figurine is estimated to have been created around $30000 \mathrm{BC}$ in the Austrian Danube Valley near Krems and is displayed at the Museum of Natural History, Vienna, Austria (Natural History Museum Vienna, with permission) (B) Neolithic Venus figurine. Clay naturalistic figurine of a seated obese woman from Farsala, Thessaly (Athanassakeion archaeological museum of Volos, Greece with permission of the Hellenic Ministry of Culture and Sports/Archaeological Resources Fund) middle Neolithic period 5800-5300 BC. ${ }^{9}$

biomarkers. The time has come to take a journey through almost 200 years of clinical research from the beginnings of NASH as a nebulous disease entity of unknown origin in the 19th century to the most frequent and vigorously investigated liver disease today.

\section{BEFORE AUTOPSY}

Obesity has been present in humans, putatively, since the European upper Palaeolithic age. This is illustrated by sculptures discovered across Europe, which are traditionally referred to as 'Venus figurines'. The most prominent example is the Venus of Willendorf (30000 BC) found in the Austrian Danube valley (figure 1A). ${ }^{8}$ In the Neolithic age (7000-3000 BC), clay obese female figurines were still popular in the Mediterranean area (figure 1B). ${ }^{9}$ Similarly, in ancient Egypt, parts of sub-Saharan Africa, China and south Pacific islands, obesity has been considered a sign of success, prosperity and good health, and in women implied fertility. ${ }^{10}$

In antiquity, obesity was first regarded as a pathological state associated with feasts and inactivity by the Indian physician Susruta (circa sixth century BC). Obesity, its comorbidities and their treatment have been described in Ayurvedic classic texts. ${ }^{11}$ In Europe, Hippocrates of Kos (460-377 BC), recognised the principal importance of healthy nutrition. ${ }^{12}$ Later, Galen of Pergamon (129-216 AD) described obesity as an illness he termed 'polysarcia'. ${ }^{13} 14$ Although Galen's ideas concerning the pathophysiology of obesity are obsolete, some of his treatments such as diet and exercise are relevant today. ${ }^{14}$

\section{AGE OF CLINICAL DIAGNOSIS AND AUTOPSY: TERM 'STEATOSIS'}

Fatty liver disease was not recognised as a disease entity until the early 19 th century. The first autopsy series revealed that hepatic steatosis affected one third of the French and German populations with female preponderance. ${ }^{15-17}$ The highest frequency of hepatic steatosis in the 1800 s was observed in patients affected by tuberculosis. ${ }^{15-19}$ In 1825 , the first edition of Louis' celebrated

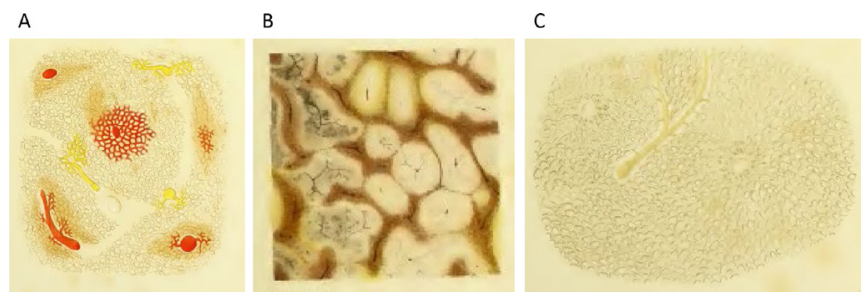

Figure 2 Historical pathology specimen of a fatty liver from T. Frerichs, Atlas of Pathological Anatomy (Part I, 1861) (A) 'fatty liver of an advanced grade'. Massive steatosis sparing the vincinity of the central veins; (B) cut surface with pale-yellow parenchyma; (C) after removal of the fat by boiling in ether, only meshes formed by the vessels remain.

anatomy and pathology textbook contained the earliest use of the term 'foie gras' (fatty liver). ${ }^{15} 20$ Fatty changes in cirrhosis were noticed as early as 1836 by Addison who introduced the term 'fatty liver' in the English medical vocabulary. ${ }^{21}$ At that time, deposition of free adipose tissue into the liver parenchyma, omentum and mesenteries was regarded as the aetiology of hepatic steatosis. ${ }^{19}$ The causal relationship between hepatic fat accumulation and fibrosis development was first recognised by the Viennese pathologist Rokitansky in $1839 .^{22}$

In 1856, Frerichs distinguished between 'a liver merely abounding in fat' and 'one which has undergone fatty degeneration'. ${ }^{17}$ The general reversibility of hepatic steatosis after diet changes was also recognised. ${ }^{17}$ In addition, progression to terminal stages with 'granular' (cirrhotic) liver, ascites and splenomegaly was observed and liver failure was termed 'foie inactive'. 1823

Intriguingly, it was already recognised by Frerichs that microscopic liver 'fatty degeneration' occurs close to inflammatory infiltrates and fibrosis (figure 2). ${ }^{17}$ In contrast, 'simple deposition of fat in cells which were not altered in their other characters' was defined as 'fatty infiltration'. This distinction resembles the differentiation between bland steatosis (NAFL) and progressive fatty liver disease (NASH and beyond) used today. By the end of the 19th century, hepatitis had been accepted as 'the second stage' thus representing the early recognition of a disease spectrum in NAFLD. ${ }^{24}$

Frerichs described 'distended cells"17 while Lereboullet ${ }^{25}$ coined the term 'cloudy swelling'. ${ }^{26}$ The morphological description is similar to what is now regarded as hepatocellular ballooning. Grading of steatosis, assessed as percentage of affected hepatocytes, was established by Frerichs. ${ }^{17}$

These histological observations were made on autopsy material. A clinical diagnosis could only be made in vivo by palpation of a rounded margin of the enlarged liver. ${ }^{16}$ The clinical association of fatty liver with diabetes and obesity were first made by Pepper $^{27}$ and Bartolow, ${ }^{28}$ respectively.

\section{PATHOLOGICAL CLASSIFICATION AND CLINICAL DESCRIPTIONS OF THE DISEASE: FIRST BIOPSY SERIES}

Most early reports on fatty liver disease came from pathologists. ${ }^{29}$ Hanssen, a clinician at the Steno Memorial Hospital in Copenhagen, Denmark described hepatomegaly due to fat accumulation in diabetic patients ${ }^{30}$ but it was Connor, a pathologist at the University of California San Francisco, USA who in 1938 described the histopathological features of fatty liver disease in diabetics and its association with development of cirrhosis indicating for the first time an aetiological link ${ }^{31}$ and put the stage for many other studies. In 1950s, possible link(s) of fatty liver with morbid obesity were discussed. ${ }^{32} 33$ 
Liver biopsies for the assessment of fatty liver disease were rarely performed before 1950 and often interpreted by clinicians themselves. Serial biopsies for the assessment of fatty liver started in the early 1950 s and documented the potentially progressive nature of the disease. ${ }^{34-38}$ The 'one second biopsy of the liver' introduced by Menghini in the late 1950s contributed to the rapid dissemination of percutaneous biopsy as a routine procedure. $^{39}$

During this time, the association of fatty liver disease with diabetes mellitus became increasingly apparent and most biopsy series included diabetic patients. ${ }^{40}$ However, discrimination between ALD and NAFLD was uncommon and many investigators analysed mixed-patient cohorts. ${ }^{38}$

Notably, the grading and staging systems for steatosis and fibrosis in the 1950 s differed from current standards. In the 1950 s, livers were considered steatotic when more than $10 \%$ (today 5\%) of the parenchymal cells were fat-ladden. An accepted grading scale extended from grade 1 (10\% steatosis) to grade 4 (approaching 100\%). ${ }^{41}$ Prevalence rates of steatosis were around $60 \%$ in diabetic subjects ${ }^{42-44}$ compared with between $18 \%$ and $36 \%$ among patients with non-diabetes. ${ }^{42} 43$

There was a major discrepancy in the literature regarding the incidence of advanced fibrosis and cirrhosis and the terms 'cirrhosis' or 'portal cirrhosis' were used as synonyms for advanced fibrosis. The fibrosis staging scale ranged from 1, denoting increased periportal connective tissue extending into the lobules, up to stage 4 with 'severe distortion of lobular architecture'. Popper suggested stages A-D similar to current fibrosis staging systems. ${ }^{38} \mathrm{He}$ concluded that subdivision by septa (stage $\mathrm{B}$ beginning, stage $\mathrm{C}$ connecting) is the basic mechanism of cirrhosis formation.

From the turn of the century until 1955, general autopsy series in the United States revealed a continuous increase in the prevalence of cirrhosis from $13 \%$ to approximately $20 \%$, with the majority representing the 'fatty nutritional type' which included both alcoholic and NAFL. ${ }^{44}$ The prevalence of cirrhosis in diabetic autopsy series in the 1930 s to 1950 s ranged from $12.7 \%$ to as high as $44 \%$ and indicated that advanced fibrosis was frequent in poorly controlled patients with diabetes. ${ }^{4042} 45$ In parallel to these observations, a continuous increase of primary liver carcinoma was noticed in 'fatty nutritional cirrhosis' thus completing the full spectrum of NAFLD as it is appreciated today. ${ }^{44}$

Regarding pathophysiology of fatty liver disease, mitochondriopathy was first described in 1952 in a French series of liver biopsies. ${ }^{37}$ As a pathological correlate to mitochondrial dysfunction, the authors observed mitochondrial degeneration and rarefication in progressive disease. Megamitochondria within hepatocytes in NASH are currently regarded as morphological equivalents of mitochondrial dysfunction; indeed, NAFLD and NASH can be considered as mitochondrial diseases in view of important function impairment of mitochondria and their role as reactive oxygen species (ROS) sources. ${ }^{46} 47$

Attempts to correlate clinico-chemical test results with liver histology failed, with particularly poor results for early disease stages. ${ }^{35} 404348$ Frequently, before routine liver transaminase testing was introduced, even the combination of four different liver function tests was normal. ${ }^{42}$

\section{DEFINITION OF NASH: THE EMERGENCE OF 'STEATOHEPATITIS'}

With the emergence of overnutrition after World War II and increasing clinical relevance of obesity and related comorbidity, attention was finally directed to NAFLD as a part of the metabolic syndrome. ${ }^{4950}$ Over time it became increasingly clear that the underlying pathophysiology of NAFLD was fundamentally different from alcoholic steatosis. Thaler in Vienna, Austria showed that steatosis affected half of obese subjects, whereas the frequency in a random series of 10900 liver biopsies was $26.5 \% .^{51}$ The degree of steatosis in diabetic patients correlated with the extent of obesity. ${ }^{52}$ Although earlier studies had shown an increased prevalence of cirrhosis in diabetics, ${ }^{4153}$ it was Thaler who clearly noted 'a cirrhotogenic role of diabetes mellitus'. ${ }^{50}$

The term 'fatty liver hepatitis' as a surrogate of 'steatohepatitis' first appeared in 1962 in the German literature to describe fatty liver with necroinflammation. ${ }^{49}$ In this seminal paper, Thaler described the presence of inflammatory infiltrates after exclusion of concurrent diseases, which could be responsible for the pathological picture. His early reports on steatohepatitis included separate series of both alcohol-related and non-alcoholic aetiology, highlighting the similarity in histopathological appearance but differences in their clinical course. Even today, we struggle with a substantial overlap in real life, as reflected by the emergence of new acronyms, such as BASH and BAFLD for 'both' ALD and NAFLD.

Histopathological studies in obese or patients with diabetes with symptomatic liver disease ${ }^{2854-70}$ documented lesions already known in ALD that are now diagnosed as NAFL/NASH. ${ }^{71}$

Despite considerable similarities, NAFLD/NASH and ALD differ in certain morphological aspects. For example, central veno-occlusive lesions are usually absent in NAFLD/NASH in contrast to ALD, and the presence of abundant, large, wellformed, Mallory-Denk bodies (MDBs) with surrounding neutrophil infiltration (satellitosis) points to an alcohol-related aetiology. ${ }^{72} 73$ Previously, others generated the hypothesis that the observed inflammatory changes could be caused by other pathogenetic influences. ${ }^{35}$ Thaler recognised that inflammation evolved independently of the degree of fatty change and he first used the term 'non-alcoholic' ${ }^{74} 75$ Over time, the term 'fatty liver hepatitis' gained broader acceptance. ${ }^{54}$

The term 'NASH' in the English language was coined by Jurgen Ludwig from the Mayo Clinic, Rochester, Minnesota, USA in 1980, who defined the 'hitherto unnamed liver disease that histologically mimics alcoholic hepatitis and that also may progress to cirrhosis'. ${ }^{76}$ However, the term 'non-alcoholic' was already in use by European and Japanese authors to describe patients with this disease. ${ }^{6377}$ The Mayo team described the histopathological hallmarks characterised by the presence of lobular hepatitis, focal necrosis with mixed inflammatory infiltrates, and in most instances MDBs and fibrosis. For the first time, the disease had been clearly linked to a pathophysiological scenario of obesity and comorbidities such as diabetes mellitus. In 1988, Thaler added the term 'ballooning' for what had previously been described as 'cloudy swelling' of damaged hepatocytes to complete the NASH criteria of today's scoring systems. ${ }^{75}$ Still, in 1990, both terms 'fatty liver hepatitis' and 'steatohepatitis' were used. ${ }^{78}$ These descriptions triggered an exponential growth of research on NASH since 1980 (figure 3). Recently, the term metabolic dysfunction-associated fatty liver disease (MAFLD) has been proposed to emphasise this association but unfortunately it may also cover other forms of metabolic liver disease with steatosis. ${ }^{1}$

NASH is a progressive disorder characterised by steatosis, hepatocyte damage, lobular inflammation and fibrosis with centrilobular (zone 3) pattern of injury in adult patients (figure 4). In paediatric NASH, portal predominance of the characteristic lesions or mixed forms are more frequent than 
600

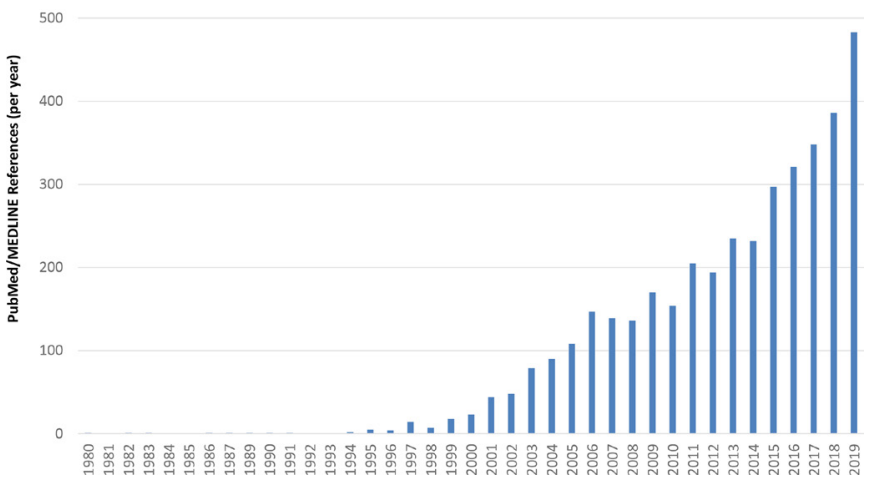

Figure 3 Numbers of annual PubMed/MEDLINE references for the term 'NASH' from 1980 to 2019. References were identified for the search term 'NASH' (excluding author names), accessed on 8 April 2020. NASH, non-alcoholic steatohepatitis.

the zone 3 pattern which is commoner in older children. ${ }^{79}$ Together with lobular infiltration by neutrophils and/or mononuclear cells, enlarged 'ballooned' hepatocytes with lightly stained, rarified cytoplasm and often a hyperchromatic nucleus with enlarged nucleolus are a diagnostically decisive feature of $\mathrm{NASH}$; they often, but not always, contain irregular eosinophilic cytoplasmic inclusions resembling MDBs. ${ }^{80}{ }^{81} \mathrm{MDBs}$ are, however, not specific for NASH and can occur in other chronic liver diseases, such as chronic cholestatic and metabolic disorders, and in hepatocellular carcinoma (HCC). ${ }^{82} 83 \mathrm{MDBs}$, originally described in 1911 by Mallory, a pathologist at Boston City Hospital, MA, USA in alcoholic cirrhosis, ${ }^{84}$ display an irregular filamentous ultrastructure and consist of partially degraded, misfolded and cross-linked keratins (particularly keratin 8), ubiquitin, stress and adaptor protein sequestosome1/p62, and heat-shock proteins, as revealed by chemical and immunohistochemical analyses. ${ }^{81-83}$ Diminution or even disappearance of the keratin intermediate filament cytoskeleton, as demonstrated by immunohistochemistry, is a characteristic feature of ballooned hepatocytes and may compromise cell stability and intracellular organisation; impaired secretory capacity and retention

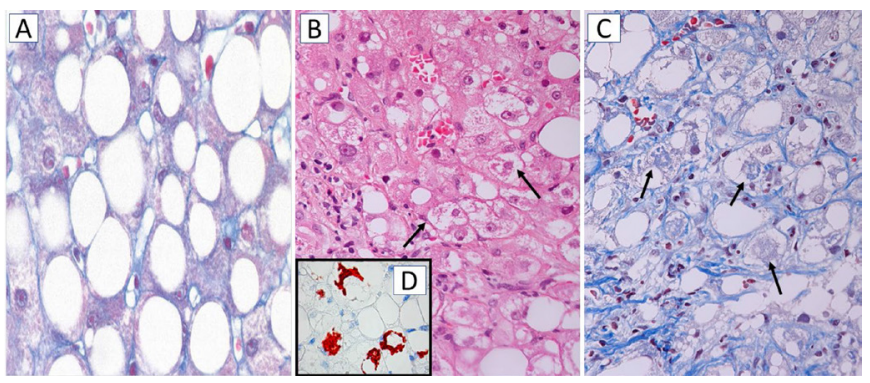

Figure 4 Histology of steatosis and non-alcoholic steatohepatitis (NASH). (A) Macrovesicular steatosis. The hepatocytes are distended by large fat droplets; chromotrope-aniline blue, $x 200$. (B) NASH characterised by ballooned hepatocytes with lightly stained cytoplasm, some of them containing indistinct cytoplasmic inclusions resembling Mallory-Denk bodies (MDBs; arrows); H\&E stain, x200. (C) NASH with ballooned hepatocytes, some of them containing MDBs (arrows) most hepatocytes are surrounded by pericellular fibrosis (blue RIMs around hepatocytes); chromotrope-aniline blue stain x200. (D, inset) Immunohistochemistry using antibodies to sequestosome1/p62 reveals p62-containing MDBs (red), x200. of proteins and fluid may also be involved. ${ }^{82} 85$ Disturbance of the keratin system adversely affects hepatocyte viability and function, since keratins are regarded as 'guardians of the cell'. Morphologically, ballooned hepatocytes resemble stressinduced (oxidative) senescent cells with abnormal synthesis of stress proteins (keratins, heat shock protein, p62 and others) as adaptation and survival strategies. They may contribute to inflammation and fibrosis. ${ }^{83} 86$

By the 1990s, the field was prepared to further study the clinical course of this newly named, old disease. It soon became clear that NASH is not just a disease in obese women with diabetes. ${ }^{87}$ Bacon et al at Saint Louis University Hospital, Missouri, USA described a substantial proportion of males and non-obese patients with normal glucose and lipid levels in their cohort. This report emphasised 'the need to consider NASH as a definite diagnostic possibility in an expanded group of patients'. ${ }^{87}$ While earlier reports described this disease entity as a rather benign and only slowly progressive disorder, ${ }^{88} 89$ the progressive nature of NASH had become clear from combined analyses of cohorts, where $43 \%$ of patients developed fibrosis. ${ }^{87-89}$ These observations were then challenged by Day's group at Newcastle University, UK, who observed normal liver enzymes in the majority NAFLD patients and no progression to cirrhosis or liver-related death at a median follow-up of 11 years. ${ }^{90}$ This challenge was further supported by observations in a cohort of 1515 morbidly obese patients where cirrhosis prevalence was only $3 \%$ despite an $80 \%$ steatosis rate. ${ }^{91}$ By the end of the 1990s, pathophysiological studies in rodents and humans supported the importance of specific events like oxidative stress and endotoxin-mediated cytokine release triggering the development of necroinflammation in NASH patients. ${ }^{92}$ Still, a likely contributor to the confusion was due to the term 'NASH' being frequently used not in the specific context of histopathological steatohepatitis. ${ }^{93}$

As liver enzymes were introduced into routine automated testing platforms, investigating apparently healthy patients with abnormal liver blood tests became a relevant issue. ${ }^{90}$ Two distinct groups of adult NAFLD patients emerged: those with simple fatty liver who had an excellent prognosis and those with progressive NASH and often fibrosis. ${ }^{93}$ Poorer outcomes were observed more frequently in patients with ballooning, MDBs or fibrosis. ${ }^{94}$ Matteoni et al from the Mayo Clinic showed that more than $20 \%$ of patients with these lesions together with inflammation developed cirrhosis over a 10 -year follow-up in contrast to only $4 \%$ of those with simple steatosis. ${ }^{94}$

In early 2000, the first studies on paediatric NAFLD documented progression to cirrhosis in $3 \%$ of the cases. ${ }^{95} 96$ Most cases are aetiologically related to the metabolic syndrome but some are due to inherited syndromes characterised by obesity and insulin resistance. ${ }^{71} 97$ The first histological autopsy study, conducted at the University of California San Diego, USA in 2006, showed a $9.6 \%$ prevalence of fatty liver in children. ${ }^{98}$

Despite the emerging awareness among specialised liver centres, surprisingly little attention was being paid to NASH in regular clinical practice. ${ }^{93}$ One ongoing challenge is the lack of a predictable correlation between abnormal standard liver tests (such as aminotransferases) and the severity of histological lesions. ${ }^{99} 100$ This has contributed to the under-recognition of NASH, particularly in patients with so-called cryptogenic cirrhosis. ${ }^{101102}$ Diagnosis of NAFLD in lean subjects is of particular importance since $20 \%$ of these patients have NASH, >F2 fibrosis and carotid atherosclerosis. ${ }^{102}$ Furthermore, NAFLD is recognised as the most common cause of cryptogenic cirrhosis but the diagnosis frequently appears to be delayed. ${ }^{103}$ 


\section{SEMIQUANTIFICATION OF NASH: HISTOLOGICAL SCORING SYSTEMS}

From the study of Matteoni et al, ${ }^{94}$ it became clear that specific histopathological features discriminated between two prognostically different patient groups. ${ }^{94}$ Different scoring systems were established to quantify the lesions and assign qualitative and semiquantitative numerical values to the histopathological diagnoses of steatosis alone, steatohepatitis and fibrosis. In 1999, Brunt et al published a histological system for assessment of 'activity' grade and staging fibrosis in NASH.${ }^{104} \mathrm{NASH}$ grades (1-3) were based on the combination of steatosis, hepatocellular ballooning, lobular and portal inflammation. Fibrosis staging recognised early zone 3 sinusoidal and/or pericellular 'chickenwire' fibrosis either alone (stage 1) or in combination with periportal (stage 2) or bridging fibrosis (stage 3), while stage 4 was cirrhosis. ${ }^{104}$

The necessity to define a widely accepted scoring system for NASH was highlighted by a National Institutes of Health symposium which fostered further efforts. ${ }^{105}$ The NASH Clinical Research Network (NASH CRN) established and validated the NASH CRN score as the first globally accepted, scoring system that addressed the full spectrum of NAFLD lesions and proposed the summative NAFLD activity score (NAS) to semiquantify disease activity in clinical trials. ${ }^{106}$ The NAS (range $0-8$ ) is calculated by summing-up semi-quantitative scores for three of the most important histological features of NAFLD: steatosis (0-3), lobular inflammation (0-2) and hepatocellular ballooning (0-2) Kleiner et al of the NASH CRN Pathology Committee initially observed that NAS $>5$ correlated with NASH diagnosis whereas biopsies with NAS scores of $<3$ correlated with 'not NASH'. Subsequent work from the same group made clear, however, that these NAS threshold values were not always associated with the underlying histological diagnosis of simple steatosis or steatohepatitis and, therefore, could not replace histopathological assessment. ${ }^{107}$ The NASH CRN pathologists have also coined the pattern-based 'borderline NASH' category for those cases that could not be binary classified. They also devised a staging system for assessing fibrosis in NAFLD based on Brunt's 5 -tier staging $(0-4)^{104}$ with only modification being the subdivision of stage 1 into 3 substages. ${ }^{106}$

In 2011, a research workshop of the American Association for the Study of Liver Diseases reached consensus on key endpoints and the design of clinical trials for adult NASH. ${ }^{108}$ It was agreed that "definite steatohepatitis" is characterised by zone 3 accentuation of macrovesicular steatosis of any grade, hepatocellular ballooning of any degree, and lobular inflammation of any degree and recommended that the NAS should be used to semiquantify disease activity. ${ }^{109}$

Grading and staging of morphological features enhance information particularly in clinical trials. NAFLD heterogeneity reflects individual variability in response to metabolic stress and susceptibility to hepatocyte lipotoxicity, depending on genetic and environmental factor. ${ }^{110}$ As shown by pioneers in the field, NAFLD displays a continuous spectrum of hepatocytic, inflammatory and fibrous lesions. Therefore, the binary categorisation of NAFLD into NASH and 'not NASH' is artificial in a continuous disease process. ${ }^{110}$ Bedossa et al developed a simple algorithm to standardise the histological diagnosis of NASH and reduce inter-observer variability. The diagnostic algorithm was informed by scores for steatosis ( $\mathrm{S} 0-\mathrm{S} 3$ ), activity grade (A0-A4 by adding scores for ballooning $(0-2)$ and lobular inflammation $(0-2))$ and fibrosis stage (F0-F4). ${ }^{11}$ A group of expert hepatopathologists and general pathologists from the Fatty Liver
Inhibition of Progression (FLIP) consortium further validated the FLIP algorithm. ${ }^{112}$ The SAF scoring system (Steatosis, Activity, Fibrosis) includes the same categories as NAS for the semiquantitation of liver injury but the diagnostic FLIP algorithm requires the simultaneous presence of steatosis, ballooning and lobular inflammation for NASH diagnosis. ${ }^{110} 111$

Despite the use of widely accepted minimal diagnostic criteria for diagnosing $\mathrm{NASH}$, the issue of interobserver variability for assessing the characteristic histological features still remains. In order to increase the reliability of NASH diagnosis, both NASH CRN and FLIP SAF scoring systems are now simultaneously used in clinical trials and registries worldwide and can be performed by expert and general pathologists equally well if they are properly trained. ${ }^{112113}$

\section{THE ROLE OF FIBROSIS AS PROGNOSTIC INDICATOR}

The prognostic relevance of these histopathological scores has been validated in several large registries with up to four decades follow-up. Fibrosis starts in zone 3 (perivenular, sinusoidal, pericellular). In later stages, portal, periportal and bridging fibrosis leads, finally, to cirrhosis. ${ }^{71-73}$ In 2015 , it became clear that evaluation of fibrosis stage may be even more fundamental than scoring necroinflammation or diagnosing NASH since it emerged as the main prognostic factor. ${ }^{114} 115$ In two independent cohorts, the American PRELHIN study and the cohort from Karolinska and Linköping University Hospital, Sweden, NAS score alone was unable to predict overall mortality, whereas fibrosis stage predicted both overall and disease-specific mortality. ${ }^{115}$ Similar results were obtained for SAF score, which was not associated with increased mortality in NAFLD after adjustment for fibrosis. ${ }^{116}$ In the largest retrospective cohort study from Karolinska and Linköping University Hospital, Sweden from 1971 to 2009, the presence of NASH alone did not significantly increase the risk of liver-specific morbidity or overall mortality during a mean 20-year follow-up. ${ }^{117}$ In recent systematic meta-analyses, the risk of liver-related mortality increased exponentially with increasing fibrosis stage, ${ }^{118}$ while biopsy-confirmed fibrosis was associated with overall mortality risk in NAFL/NASH patients after adjusting for confounding factors. ${ }^{119}$ Further dissecting the natural course of advanced disease, a multinational study of 458 patients documented that patients with NAFLD cirrhosis have predominantly liver-related events, whereas those with bridging fibrosis experience mainly extrahepatic malignancy and cardiovascular events. ${ }^{120}$ In 475 NASH patients enrolled in two negative phase $2 \mathrm{~b}$ trials, the primary determinant of clinical disease progression was fibrosis extent, fibrosis at baseline and its change over time. ${ }^{121}$

Although cirrhosis is the major risk factor for HCC development in NAFLD, there is increasing evidence that NAFLD-associated HCC frequently occurs in the absence of cirrhosis. ${ }^{122} 123$

The role of NASH as a precursor lesion for fibrosis emerged as patients with NASH developed severe liver disease slightly earlier than patients without NASH in the Swedish cohort. ${ }^{117}$ Recently, two positive NASH CRN clinical trials demonstrated a strong association between improvements in fibrosis and resolution of steatohepatitis. ${ }^{124}$ In addition, an NASH CRN prospective study has shown that changes in NAFLD activity are positively associated with changes in fibrosis. ${ }^{125}$ The general reversibility of ballooning, lobular inflammation and fibrosis after weight loss has been documented in patients undergoing bariatric surgery. ${ }^{126}$ Whether histopathological improvement from liver biopsy data in fact translates into a reduction in overall mortality and liverrelated events is currently being investigated in phase 3 studies. 
In 2021, liver biopsy still remains the only diagnostic procedure that can reliably assess the various NAFLD patterns, and particularly to diagnose NASH and early fibrosis. ${ }^{71} 113$

\section{GENETIC BASIS OF NAFLD PHENOTYPES}

At the turn of 21st century, large-scale sequencing techniques became more widely available at reasonable cost. Genome-wide association (GWAS) and candidate gene studies have contributed to our understanding of interindividual variation in the progression and outcome of ALD and NAFLD. ${ }^{127}$ Genetic variants influence the risk and fate of NAFLD, particularly intensity and effects of oxidative stress, severity of steatosis and fibrosis, response to endotoxin, release of cytokines/chemokines and immune response. In 2008, Romeo and colleagues published the first GWAS in NAFLD. ${ }^{128}$ Of relatively modest size by current standards, this study examined 9229 nonsynonymous single-nucleotide polymorphisms (SNPs) in a North American population of diverse ethnicity from the Dallas Heart Study and identified a single highly significant association between increased hepatic triacylglycerol accumulation measured using non-invasive proton MR spectroscopy and the patatin-like phospholipase domain-containing 3 (PNPLA3) gene locus. Ethnic differences were described for the p.I148M SNP that was most common in Hispanics, lower in subjects of European ancestry (0.23) and lowest in African-Americans. ${ }^{128}$ Together with further SNPs associated with increased hepatic triacylglycerol content, PNPLA3 has been confirmed in a subsequent GWAS meta-analysis using 2.4 million SNPs from 7176 individuals of European ancestry by Speliotes et al. ${ }^{129}$ This variant may explain, at least in part, special phenotypes like paediatric and lean NAFLD. ${ }^{130} 131$ The search for further fatty liver genes revealed transmembrane 6 superfamily member 2 (TM6SF2), glucokinase regulatory protein gene (GCKR), and HSD17B13, encoding for a retinol dehydrogenase, among an increasing list of associated loci. ${ }^{127}{ }^{132-134}$ Combined effects of these risk alleles were observed in replication cohorts. ${ }^{133}$ In recent years, additional data supported the particular contribution of PNPLA3 and other gene loci to the development of fibroinflammation and HCC. ${ }^{127}$ In the largest histology-based NAFLD GWAS in a cohort of 1483 European patients with biopsy-proven NAFLD and 17781 genetically matched controls, PNPLA3 was confirmed as risk factor for the full histological spectrum of NAFLD, while TM6SF2, GCKR and HSD17B13 were also confirmed as NAFLD risk modifiers. ${ }^{135}$ Combining the number of inherited NAFLD risk genes with the multitude of exogenous NAFLD risk factors (exposome), threedimensional risk-space models allow visualisation of disease trajectory in NAFLD risk gene carriers over time. ${ }^{136}$ It is tempting to speculate that genotyping will guide our clinical practice in the future but it has not as yet entered clinical practice because the effect magnitude of PNPLA3 risk allele for NASH development or liver cancer is rather modest. ${ }^{137} 138$

\section{TOWARDS NON-INVASIVE DIAGNOSIS OF NASH AND FIBROSIS IN NAFLD: FUTURE TRENDS}

Research on NAFLD has made remarkable progress over the past two centuries (figure 5) but major issues remain. Despite progress in non-invasive tests (NITs) for the evaluation of liver fibrosis in NAFLD, such as elastography devices and blood tests, ${ }^{139}$ the diagnosis of NASH is still based on liver biopsy, an invasive procedure not suitable for the large proportion of general population affected by NAFLD. In 2007, the NAFLD fibrosis score (NFS) was introduced as a simple scoring system to distinguish NAFLD with and without advanced fibrosis. ${ }^{140}$ Subsequently, further fibrosis tests (table 1), including fibrosis-4 (FIB-4) index, ${ }^{141}$ fibrotest/fibrosure, ${ }^{142}$

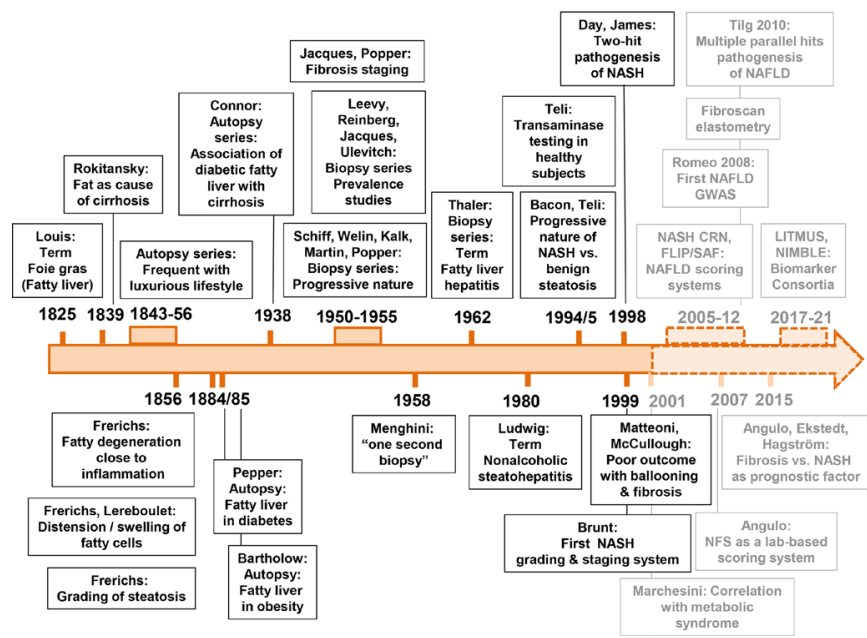

Figure 5 Timeline of major developments in the field of NAFLD over the past 200 years. Major landmarks in the field until 2000 are shown with solid lines and black font, while developments after 2000 that cannot yet be viewed in a historical context are shown in dashed lines and lighter font. NAFLD, non-alcoholic fatty liver disease.

enhanced liver fibrosis test ${ }^{143}$ and liver stiffness measurement by vibration-controlled transient elastography, ${ }^{144}$ have entered clinical practice. Most importantly for primary care, these NITs show excellent area under the receiver operating characteristic (AUROCs) for the diagnosis of advanced fibrosis and cirrhosis. ${ }^{145}$ The non-invasive diagnosis of advanced fibrosis has been further improved by the sequential combination of different NITs thereby refining the patient referral pathway between primary care or diabetologists and liver specialists. ${ }^{146}$ Longitudinal retrospective studies have demonstrated that NITs calibrated on liver fibrosis are themselves prognostic markers able to stratify the risk of

\begin{tabular}{lll}
\hline Table 1 & Non-invasive tests for fibrosis assessment in NAFLD \\
\hline Direct serum markers & $\begin{array}{l}\text { Indirect serum markers/ } \\
\text { panels }\end{array}$ & $\begin{array}{l}\text { Combined scores/ } \\
\text { algorithms }\end{array}$ \\
\hline Hyaluronic Acid $\left({ }^{158}\right)$ & AST/ALT $\left({ }^{141}\right)$ & Fibrotest $\left({ }^{142}\right)$ \\
Laminin $\left({ }^{159}\right)$ & $\gamma$-GT & Hepascore $\left({ }^{167}\right)$ \\
YKL-40 $\left({ }^{160}\right)$ & Platelet count & Fibrospect $\left({ }^{168}\right)$ \\
Procollagen type-III N- & Albumin & Fibrometer $\left({ }^{169}\right)$ \\
terminal peptide (Pro-C3) & PGA $\left({ }^{164}\right)$ & Forns score $\left({ }^{170}\right)$ \\
$\left({ }^{161}\right)$ & APRI $\left({ }^{165}\right)$ & BAAT score $\left({ }^{171}\right)$ \\
Metalloproteinases & Cytokeratin-18* $\left({ }^{166}\right)$ & BARD Score $\left({ }^{172}\right)$ \\
MMP-1, MMP-2 $\left({ }^{162}\right)$ & & ELF $\left({ }^{143}\right)$ \\
TIMPs $\left({ }^{158}\right)$ & & FIB-4 score $\left({ }^{141}\right)$ \\
TGF- $\beta 1 *{ }^{*}\left({ }^{163}\right)$ & & NAFLD fibrosis score $\left({ }^{140}\right)$ \\
& & MACK-3 score* $\left({ }^{173}\right)$ \\
& & eLIFT $\left({ }^{174}\right)$ \\
& HEPAmet fibrosis
\end{tabular}

*Denotes tests also assessed for non-invasive diagnosis of NASH. ALT, alanine aminotransferase; APRI, AST to Platelet Ratio Index; AST, aspartate aminotransferase; BAAT, $\underline{B} M I$, age, $\underline{A}$ LT, Triglyceride score; BARD, BMI, $\underline{A}$ ST/ALT Ratio, Diabetes score; BMI, body mass index; ELF, European Liver Fibrosis panel; eLIFT, easy Liver Fibrosis Test; FAST, Fibroscan-AST; FIB-4 score, Fibrosis-4; $\gamma$-GT, gammaglutamyl transferase; MACK-3, combination of HOMA, AST and CK18; NAFLD, non-alcoholic fatty liver disease; NIS-4, non-Invasive diagnosis for non-alcoholic Steatohepatitis panel; PGA, Prothrombin time, Gamma-glutamyl transpeptidase, Apoliprotein Al; PIIINP, Procollagen III amino terminal peptide; TGF- $\beta 1$, transforming growth factor- $\beta$; TIMPs, tissue inhibitors of metalloproteinases; YLK-40, chondrex, human cartilage glycoprotein-39. 
liver-related outcomes and mortality in NAFLD. ${ }^{147} 148$ These data reinforce the relevance of using NITs instead of liver biopsy for the management of NAFLD patients in clinical practice.

NITs, such as the multiparametric NIS4 test, ${ }^{149}$ have not yet achieved sufficient accuracy and validation for the non-invasive diagnosis of NASH in routine practice. This, therefore, remains a significant challenge, and large consortia (LITMUS in Europe, NIMBLE in USA) are currently working to identify and validate new NASH biomarkers.

Pathological diagnosis in the near future will be supported by artificial intelligence. Future attempts to improve NASH diagnosis will apply machine learning to develop fully automated software applications for quantification of steatosis, inflammation, ballooning and fibrosis. ${ }^{150}$ Advances in microscopy techniques, such as second harmonic generation/two-photon excitation fluorescence imaging, could potentially improve reproducibility and standardisation of liver biopsy assessment. ${ }^{151}$

A great deal of our previously discussed knowledge has been derived from animal experiments under standardised conditions. ${ }^{152}$ Efforts are now focused on next-generation mouse models, which are particularly suitable for genetic manipulation but out of the focus of this work. ${ }^{153}$

What will the future bring in regard to NAFLD? As the global epidemic of obesity fuels metabolic conditions, the clinical and economic burden of NAFLD will become enormous. ${ }^{154}$ Models based on published estimates predict a growth of up to $30 \%$ in total NAFLD cases between 2016 and 2030. ${ }^{155}$ NASH prevalence will increase by $15 \%-56 \%$, while advanced liver disease and liverrelated mortality will more than double as a result of ageing Western populations. Obeticholic acid could represent an important milestone in the history of NASH if it becomes the first licensed treatment based on the favourable results of the interim analysis of the pivotal phase 3 trial. ${ }^{156}$ For those with morbid obesity, rates of bariatric procedures will further increase. ${ }^{157}$ Given the rapidly growing global burden of NAFLD/NASH, efforts to discover accurate, non-invasive diagnostic and prognostic biomarkers, to develop effective treatments for individuals with advanced NASH and to implement preventive methods must continue. ${ }^{4}$ The remark of Louis from 1843 on NAFLD as the most frequent and significant disease of the liver is still true today and guides our efforts in the future. ${ }^{15}$

Correction notice This article has been corrected since it published Online First. The second author affiliation has been amended and the funding and competing interests statements added.

Twitter Dina Tiniakos @Dina Tiniakos

Acknowledgements The authors thank Ms Alexandra Weisgram for her excellent secretarial assistance and Dr Camilla Graham for language editing and insightful comments.

\section{Collaborators None.}

Contributors Concept and supervision: AG and MT; acquisition of data: AG, DT, $\mathrm{HD}$ and MT; analysis and interpretation of data: AG, DT, HD and MT; drafting of the manuscript: $A G$ and $M T$; critical revision of the manuscript for important intellectual content: AG, DT, HD and MT; obtained funding: AG, DT and MT; material support: AG, DT and HD.

Funding This work has been supported by the Liver Investigation: Testing Marker Utility in Steatohepatitis (LITMUS) project. The LITMUS project has received funding from the Innovative Medicines Initiative 2 Joint Undertaking under grant agreement no 777377. This Joint Undertaking receives support from the European Union's Horizon 2020 research and innovation programme and EFPIA.

Competing interests AG has declared receiving grants from Intercept, Novartis, Exalenz, Falk and Kibion and has received personal fees from Intercept, Novartis, Gilead, Pfizer, Falk, MSD, BMS, Ipsen, Sanofi-Aventis,Bayer, Eisai, CSL Behring, Sequana, Merz, Abbvie and Alexion. DT reports consultation fees from Intercept Pharmaceuticals Inc, Allergan plc, Cirius Therapeutics Inc, Alimentiv Inc, Clinnovate Health UK Ltd and an educational grant from Histoindex Pte. MT has received research grants from Albireo, Cymabay, Falk, Gilead, Intercept, MSD and Takeda and travel grants from Abbvie, Falk, Gilead and Intercept. He further has advised for Albireo, BiomX, Boehringer Ingelheim, Falk Pharma GmbH, Genfit, Gilead, Intercept, Jannsen, MSD, Novartis, Phenex, Regulus and Shire and has served as speaker for Falk Foundation, Gilead, Intercept and MSD. He is also co-inventor of patents on the medical use of NorUDCA filed by the Medical Universities of Graz and Vienna.

Patient and public involvement Patients and/or the public were not involved in the design, or conduct, or reporting, or dissemination plans of this research.

Patient consent for publication Not required.

Provenance and peer review Not commissioned; externally peer reviewed.

Open access This is an open access article distributed in accordance with the Creative Commons Attribution Non Commercial (CC BY-NC 4.0) license, which permits others to distribute, remix, adapt, build upon this work non-commercially, and license their derivative works on different terms, provided the original work is properly cited, appropriate credit is given, any changes made indicated, and the use is non-commercial. See: http://creativecommons.org/licenses/by-nc/4.0/.

\section{ORCID iDs}

Andreas Geier http://orcid.org/0000-0002-9626-5083

Michael Trauner http://orcid.org/0000-0002-1275-6425

\section{REFERENCES}

1 Eslam M, Newsome PN, Sarin SK, et al. A new definition for metabolic dysfunctionassociated fatty liver disease: an international expert consensus statement. J Hepatol 2020;73:202-9.

2 Tilg $\mathrm{H}$, Moschen AR. Evolution of inflammation in nonalcoholic fatty liver disease: the multiple parallel hits hypothesis. Hepatology 2010;52:1836-46.

3 Tilg H, Adolph TE, Moschen AR. Multiple parallel hits hypothesis in nonalcoholic fatty liver disease: revisited after a decade. Hepatology 2021;73:833-42.

4 Younossi ZM. Non-Alcoholic fatty liver disease - a global public health perspective. $J$ Hepatol 2019;70:531-44.

5 WHO. Obesity and overweight. WHO, 2018

6 Bray GA, Nielsen SJ, Popkin BM. Consumption of high-fructose corn syrup in beverages may play a role in the epidemic of obesity. Am J Clin Nutr 2004;79:537-43.

7 Jensen T, Abdelmalek MF, Sullivan S, et al. Fructose and sugar: a major mediator of non-alcoholic fatty liver disease. J Hepatol 2018;68:1063-75.

8 Antl-Weiser $W$. The time of the Willendorf figurines and new results of Palaeolithic research in lower Austria. Anthropologie2009;47:131-41.

9 Christopoulou-Aletra H, Papavramidou N, Pozzilli P. Obesity in the Neolithic era: a Greek female figurine. Obes Surg 2006;16:1112-4.

10 Sellayah D, Cagampang FR, Cox RD. On the evolutionary origins of obesity: a new hypothesis. Endocrinology 2014;155:1573-88.

11 Tipton CM. Susruta of India, an unrecognized contributor to the history of exercise physiology. J App/ Physiol 2008;104:1553-6.

12 Smith R. "Let food be thy medicine.". BMJ 2004;328:0-g.

13 Kleisiaris CF, Sfakianakis C, Papathanasiou IV. Health care practices in ancient Greece: the Hippocratic ideal. J Med Ethics Hist Med 2014;7:6.

14 Papavramidou NS, Papavramidis ST, Christopoulou-Aletra H. Galen on obesity: etiology, effects, and treatment. World J Surg 2004;28:631-5.

15 Louis PCA. Recherches anatomiques et pathologiques sur La phtisie. 2nd ed. J. B. Bailliere, 1843.

16 Lereboullet A. Memoire sur la Structure intime du Foie et sur la Nature de I' Alteration connue sous le Nom de Foie Gras. J.B. Bailliere, 1853.

17 Frerichs FT. A clinical treatise on diseases of the liver. German Edition 1856. New York: M. W. Wood, 1879

18 Bock CE. Lehrbuch Der pathologischen Anatomie und Diagnostik. Leipzig: Georg Wigand's Verlag, 1852

19 Rokitansky C. A manual of pathological anatomy. Philadelphia: Blanchard \& Lea, 1855.

20 Cruveilhier J. Anatomie pathologique Du Corps Humain. Paris: J. B. Bailliere, 1829/1842.

21 Addison T. Observations on fatty degeneration of the liver. Guy's Hospital Reports 1836:1:476.

22 Rokitansky CA. Skizze Der Grössen- und Formenabweichungen Der Leber Bruchstück. Medizinisches Jahrbuch des kaiserlich-königlichen Österreichischen Staates 1839:20:577.

23 Gauchas A. Etude sur La Steatose Hepatique consideree Au point de Vue Chirurgical. Paris: A. Delahaye \& E. Lecrosnier, Editeurs, 1882.

24 Bollinger O. Altlas and essentials of pathological anatomy. New York: William Wood \& Company, 1898

25 Lereboullet MA. M. A. Lereboullet upon the intimate structure of the liver and the nature of the alteration known under the name of fatty liver. Edinb Med Surg J $1854 ; 81: 582-5$ 
26 Ziegler E. A textbook of pathological anatomy and pathogenesis. London: MacMillan \& $\mathrm{C} 0,1884$.

27 Pepper W. Saccharine diabetes. Med Rec 1884;25:9-12.

28 Bartolow P. Diseases of the liver. In: Pepper W, Starr L, eds. A system of practical medicine. Philadelphia: Lea Brothers \& Co, 1885: Vol II. 1050.

29 Eppinger H, Leberkrankheiten D. Allgemeine und Spezielle Pathologie Der Leber. Wien: Springer, 1937.

30 Hanssen PER. Enlargement of the liver in diabetes mellitus. J Am Med Assoc 1936;106:914

31 Connor CL. Fatty infiltration of the liver and the development of cirrhosis in diabetes and chronic alcoholism. Am J Pathol 1938;14:347-64.

32 Zelman S. The liver in obesity. Arch Intern Med 1952;90:141-56.

33 Westwater JO, Fainer D. Liver impairment in the obese. Gastroenterology 1958;34:686-93

34 Weisbrod FG, Schiff L. Needle biopsy of the liver; experiences in the differential diagnosis of jaundice. Gastroenterology 1950;14:56-72.

35 Welin G. Needle biopsy and liver function in earlier stages of fatty cirrhosis of the liver. Acta Med Scand Supp/ 1950;246:260-7.

36 Kalk H. Über die Beziehungen zwischen Fettleber und Diabetes ${ }^{1}$. Dtsch med Wochenschr 1959;84:1898-901.

37 Martin M. Considerations histo-pathologiques et cliniques sur les Steatoses Du foie. Le Journal de Medicine de Lyon 1952:187-98.

38 Popper H, Szanto PB, Elias H. Transition of fatty liver into cirrhosis. Gastroenterology 1955;28:183-92.

39 Menghini G. One-Second needle biopsy of the liver. Gastroenterology 1958:35:190-9.

40 Leevy CM, Ryan CM, Fineberg JC. Diabetes mellitus and liver dysfunction; etiologic and therapeutic considerations. Am J Med 1950;8:290-9.

41 Jaques WE. The incidence of portal cirrhosis and fatty metamorphosis in patients dying with diabetes mellitus. N Eng/ J Med 1953;249:442-5.

42 Reinberg MH, Lipson M. The association of Laennec's cirrhosis with diabetes mellitus. Ann Intern Med 1950;33:1195-202.

43 Ulevitch H, Gall EA, Abernathy EL, et al. Needle biopsy of the liver. Gastroenterology 1951;18:1-7.

44 Robbins SL. Clinicopathologic correlations in fatty nutritional cirrhosis. Am J Gastroenterol 1958;30:387-92.

45 Schleusner V. Uber die Zusammenhange zwischen Diabetes mellitus und Erkrankungen der Leber und der Gallenwege. [Dissertation]. Hamburg: University of Hamburg, 1938.

46 Pessayre D, Fromenty B. Nash: a mitochondrial disease. J Hepatol 2005;42:928-40.

47 Koliaki C, Szendroedi J, Kaul K, et al. Adaptation of hepatic mitochondrial function in humans with non-alcoholic fatty liver is lost in steatohepatitis. Cell Metab 2015:21:739-46

48 Jansen L. [Diagnosis of fatty liver]. Dtsch Med Wochenschr 1956:81:742-4.

49 Thaler H. [Fatty liver, its causes and concomitant diseases]. Dtsch Med Wochenschr 1962;87:1049-55.

50 Thaler H. Relation of steatosis to cirrhosis. Clin Gastroenterol 1975;4:273-80.

51 Thaler H. [Etiology and therapy of fatty liver]. Dtsch Med J 1972;23:648-53.

52 Beringer $\mathrm{A}$, Thaler $\mathrm{H}$. Zusammenhänge zwischen Diabetes mellitus und Fettleber * Dtsch Med Wochenschr 1970:95:836-8.

53 Bloodworth JMB. Diabetes mellitus and cirrhosis of the liver. Arch Intern Med 1961;108:695-101.

54 Adler M, Schaffner F. Fatty liver hepatitis and cirrhosis in obese patients. Am J Med 1979:67:811-6.

55 Marubbio AT, Buchwald H, Schwartz MZ, et al. Hepatic lesions of central pericellular Fibros is in morbid obesity, and after jejunoileal bypass. Am J Clin Pathol 1976;66:684-91.

56 Galambos JT, Wills CE. Relationship between 505 paired liver tests and biopsies in 242 obese patients. Gastroenterology 1978;74:1191-5.

57 Nasrallah SM, Wills CE, Galambos JT. Hepatic morphology in obesity. Dig Dis Sci 1981:26:325-7.

58 Andersen T, Christoffersen P, Gluud C. The liver in consecutive patients with morbid obesity: a clinical, morphological, and biochemical study. Int J Obes 1984;8:107-15.

59 Eriksson S, Eriksson KF, Bondesson L. Nonalcoholic steatohepatitis in obesity: a reversible condition. Acta Med Scand 1986;220:83-8.

60 Klain J, Fraser D, Goldstein J, et al. Liver histology abnormalities in the morbidly obese. Hepatology 1989;10:873-6.

61 Watanabe A, Kobayashi M, Yoshitomi S, et al. Liver fibrosis in obese patients with fatty livers. J Med 1989:20:357-62.

62 Zimmerman HJ, MacMurray FG, Rappaport H. Studies of the liver in diabetes mellitus. J Lab Clin Med 1950;36:912-21.

63 Itoh S, Tsukada Y, Motomura Y, et al. Five patients with nonalcoholic diabetic cirrhosis. Acta Hepatogastroenterol 1979:26:90-7.

64 Nagore N, Scheuer PJ. The pathology of diabetic hepatitis. J Pathol 1988;156:155-60.

65 Silverman JF, O'Brien KF, Long S. Liver pathology in morbidly obese patients with and without diabetes. Am J Gastroenterol 1990;85:1349-55.
66 Batman PA, Scheuer PJ. Diabetic hepatitis preceding the onset of glucose intolerance. Histopathology 1985;9:237-43.

67 Peters RL. Hepatic morphologic changes after jejunoileal bypass. Prog Liver Dis 1979:6:581-94.

68 Hamilton DL, Vest TK, Brown BS, et al. Liver injury with alcoholiclike hyalin after gastroplasty for morbid obesity. Gastroenterology 1983;85:722-6.

69 Vyberg M, Ravn V, Andersen B. Pattern of progression in liver injury following jejunoileal bypass for morbid obesity. Liver 1987;7:271-6.

70 Silverman EM, Sapala JA, Appelman HD. Regression of hepatic steatosis in morbidly obese persons after gastric bypass. Am J Clin Pathol 1995;104:23-31.

71 Tiniakos DG, Anstee QM, Brunt EM. MacSween's pathology of the liver. 8th Ed. Philadelphia: Elsevier, 2021

72 Brunt EM. Histological assessment of nonalcoholic fatty liver disease in adults and children. Clin Liver Dis 2012;1:108-11.

73 Skoien R, Richardson MM, Jonsson JR, et al. Heterogeneity of fibrosis patterns in non-alcoholic fatty liver disease supports the presence of multiple fibrogenic pathways. Liver Int 2013:33:624-32.

74 Schaffner F, Thaler H. Nonalcoholic fatty liver disease. Prog Liver Dis 1986;8:283-98.

75 Thaler H. 10 fatty change. Baillière's Clinical Gastroenterology 1988;2:453-62.

76 Ludwig J, Viggiano TR, McGill DB, et al. Nonalcoholic steatohepatitis: Mayo clinic experiences with a hitherto unnamed disease. Mayo Clin Proc 1980;55:434-8.

77 Massarrat S, Jordan G, Sahrhage G, et al. Five-Year follow-up study of patients with nonalcoholic and nondiabetic fatty liver. Acta Hepatogastroenterol 1974;21:176-86.

78 Wanless IR, Lentz JS, hepatitis Fliver. Fatty liver hepatitis (steatohepatitis) and obesity: an autopsy study with analysis of risk factors. Hepatology 1990;12:1106-10.

79 Carter-Kent C, Yerian LM, Brunt EM, et al. Nonalcoholic steatohepatitis in children: a multicenter clinicopathological study. Hepatology 2009:50:1113-20.

80 Denk H, Franke WW, Kerjaschki D, et al. Mallory bodies in experimental animals and man. Int Rev Exp Pathol 1979;20:77-121.

81 Zatloukal K, French SW, Stumptner C, et al. From Mallory to Mallory-Denk bodies: what, how and why? Exp Cell Res 2007:313:2033-49.

82 Strnad P, Zatloukal K, Stumptner C, et al. Mallory-Denk-bodies: lessons from keratincontaining hepatic inclusion bodies. Biochim Biophys Acta 2008;1782:764-74.

83 Denk H, Abuja PM, Zatloukal K. Animal models of NAFLD from the pathologist's point of view. Biochim Biophys Acta Mol Basis Dis 2019;1865:929-42.

84 Mallory FB. Cirrhosis of the liver. five different types of lesions from which it may arise. Bull Johns Hopkins Hosp 1911;22:69-75

85 Lackner C, Gogg-Kamerer M, Zatloukal K, et al. Ballooned hepatocytes in steatohepatitis: the value of keratin immunohistochemistry for diagnosis. J Hepatol 2008:48:821-8

86 Papatheodoridi Alkistis-Maria, Chrysavgis L, Koutsilieris M, et al. The role of senescence in the development of nonalcoholic fatty liver disease and progression to nonalcoholic steatohepatitis. Hepatology 2020:71:363-74.

87 Bacon BR, Farahvash MJ, Janney CG, et al. Nonalcoholic steatohepatitis: an expanded clinical entity. Gastroenterology 1994;107:1103-9.

88 Lee RG. Nonalcoholic steatohepatitis: a study of 49 patients. Hum Pathol 1989;20:594-8

89 Powell EE, Cooksley WGE, Hanson R, et al. The natural history of nonalcoholic steatohepatitis: a follow-up study of forty-two patients for up to 21 years. Hepatology 1990;11:74-80.

90 Teli MR, James OFW, Burt AD, et al. The natural history of nonalcoholic fatty liver: a follow-up study. Hepatology 1995;22:1714-9.

91 Andersen T, Gluud C. Liver morphology in morbid obesity: a literature study. Int Obes 1984:8:97-106.

92 Day CP, James OFW. Hepatic steatosis: innocent bystander or guilty Party? Hepatology 1998;27:1463-6.

93 James OF, Day CP. Non-alcoholic steatohepatitis (NASH): a disease of emerging identity and importance. J Hepatol 1998:29:495-501.

94 Matteoni CA, Younossi ZM, Gramlich T, et al. Nonalcoholic fatty liver disease: a spectrum of clinical and pathological severity. Gastroenterology 1999:116:1413-9.

95 Sathya P, Martin S, Alvarez F. Nonalcoholic fatty liver disease (NAFLD) in children. Curr Opin Pediatr 2002;14:593-600.

96 Roberts EA. Nonalcoholic steatohepatitis in children. Curr Gastroenterol Rep 2003:5:253-9.

97 Schwimmer JB, Deutsch R, Rauch JB, et al. Obesity, insulin resistance, and other clinicopathological correlates of pediatric nonalcoholic fatty liver disease. J Pediat 2003;143:500-5.

98 Schwimmer JB, Deutsch R, Kahen T, et al. Prevalence of fatty liver in children and adolescents. Pediatrics 2006:118:1388-93.

99 Ma X, Liu S, Zhang J, et al. Proportion of NAFLD patients with normal ALT value in overall NAFLD patients: a systematic review and meta-analysis. BMC Gastroenterol 2020;20:10.

100 Fracanzani AL, Valenti L, Bugianesi E, et al. Risk of severe liver disease in nonalcoholic fatty liver disease with normal aminotransferase levels: a role for insulin resistance and diabetes. Hepatology 2008;48:792-8.

101 Caldwell SH, Oelsner DH, lezzoni JC, et al. Cryptogenic cirrhosis: clinical characterization and risk factors for underlying disease. Hepatology 1999;29:664-9. 
102 Fracanzani AL, Petta S, Lombardi R, et al. Liver and cardiovascular damage in patients with lean nonalcoholic fatty liver disease, and association with visceral obesity. Clin Gastroenterol Hepatol 2017;15:1604-11.

103 Clark JM, Diehl AM. Nonalcoholic fatty liver disease: an underrecognized cause of cryptogenic cirrhosis. JAMA 2003;289:3000-4.

104 Brunt EM, Janney CG, Di Bisceglie AM, et al. Nonalcoholic steatohepatitis: a proposal for grading and staging the histological lesions. Am J Gastroenterol 1999:94:2467-74.

105 James *Oliver, Day C. Non-Alcoholic steatohepatitis: another disease of affluence. Lancet 1999;353:1634-6.

106 Kleiner DE, Brunt EM, Van Natta M, et al. Design and validation of a histological scoring system for nonalcoholic fatty liver disease. Hepatology 2005;41:1313-21.

107 Brunt EM, Kleiner DE, Wilson LA, et al. Nonalcoholic fatty liver disease (NAFLD) activity score and the histopathologic diagnosis in NAFLD: distinct clinicopathologic meanings. Hepatology 2011:53:810-20.

108 Sanyal AJ, Brunt EM, Kleiner DE, et al. Endpoints and clinical trial design for nonalcoholic steatohepatitis. Hepatology 2011;54:344-53.

109 Suzuki A, Diehl AM. Nonalcoholic steatohepatitis. Annu Rev Med 2017;68:85-98.

110 Bedossa P. Current histological classification of NAFLD: strength and limitations. Hepatol Int 2013;7:765-70.

111 Bedossa P, Poitou C, Veyrie N, et al. Histopathological algorithm and scoring system for evaluation of liver lesions in morbidly obese patients. Hepatology 2012:56:1751-9.

112 Bedossa P, FLIP Pathology Consortium. Utility and appropriateness of the fatty liver inhibition of progression (FLIP) algorithm and steatosis, activity, and fibrosis (SAF) score in the evaluation of biopsies of nonalcoholic fatty liver disease. Hepatology 2014;60:565-75

113 Brunt EM, Kleiner DE, Carpenter DH. American association for the study of liver diseases NASH Task force. nonalcoholic fatty liver disease: reporting histologic findings in clinical practice. Hepatology. In Press 2020

114 Angulo P, Kleiner DE, Dam-Larsen S, et al. Liver fibrosis, but no other histologic features, is associated with long-term outcomes of patients with nonalcoholic fatty liver disease. Gastroenterology 2015;149:389-97.

115 Ekstedt M, Hagström H, Nasr P, et al. Fibrosis stage is the strongest predictor for disease-specific mortality in NAFLD after up to 33 years of follow-up. Hepatology 2015;61:1547-54.

116 Hagström H, Nasr P, Ekstedt M, et al. Saf score and mortality in NAFLD after up to 41 years of follow-up. Scand J Gastroenterol 2017;52:87-91.

117 Hagström H, Nasr P, Ekstedt M, et al. Fibrosis stage but not NASH predicts mortality and time to development of severe liver disease in biopsy-proven NAFLD. J Hepatol 2017:67:1265-73.

118 Dulai PS, Singh S, Patel J, et al. Increased risk of mortality by fibrosis stage in nonalcoholic fatty liver disease: systematic review and meta-analysis. Hepatology 2017:65:1557-65.

119 Taylor RS, Taylor RJ, Bayliss S, et al. Association between fibrosis stage and outcomes of patients with nonalcoholic fatty liver disease: a systematic review and metaanalysis. Gastroenterology 2020;158:1611-25

120 Vilar-Gomez E, Calzadilla-Bertot L, Wai-Sun Wong V, et al. Fibrosis severity as a determinant of cause-specific mortality in patients with advanced nonalcoholic fatty liver disease: a multi-national cohort study. Gastroenterology 2018;155:443-57.

121 Sanyal AJ, Harrison SA, Ratziu V, et al. The natural history of advanced fibrosis due to nonalcoholic steatohepatitis: data from the simtuzumab trials. Hepatology 2019;70:1913-27.

122 Bertot LC, Adams LA. Trends in hepatocellular carcinoma due to non-alcoholic fatty liver disease. Expert Rev Gastroenterol Hepatol 2019;13:179-87.

123 Piscaglia F, Svegliati-Baroni G, Barchetti A, et al. Clinical patterns of hepatocellular carcinoma in nonalcoholic fatty liver disease: a multicenter prospective study. Hepatology 2016;63:827-38.

124 Brunt EM, Kleiner DE, Wilson LA, et al. Improvements in histologic features and diagnosis associated with improvement in fibrosis in nonalcoholic steatohepatitis: results from the nonalcoholic steatohepatitis clinical research network treatment trials. Hepatology 2019;70:522-31.

125 Kleiner DE, Brunt EM, Wilson LA, et al. Association of histologic disease activity with progression of nonalcoholic fatty liver disease. JAMA Netw Open 2019:2:e1912565.

126 Lassailly G, Caiazzo R, Buob D, et al. Bariatric surgery reduces features of nonalcoholic steatohepatitis in morbidly obese patients. Gastroenterology 2015;149:379-88.

127 Anstee QM, Seth D, Day CP. Genetic factors that affect risk of alcoholic and nonalcoholic fatty liver disease. Gastroenterology 2016;150:1728-44.

128 Romeo S, Kozlitina J, Xing C, et al. Genetic variation in PNPLA3 confers susceptibility to nonalcoholic fatty liver disease. Nat Genet 2008:40:1461-5.

129 Speliotes EK, Yerges-Armstrong LM, Wu J, et al. Genome-wide association analysis identifies variants associated with nonalcoholic fatty liver disease that have distinct effects on metabolic traits. PLoS Genet 2011;7:e1001324.

130 Krawczyk M, Liebe R, Maier IB, et al. The frequent adiponutrin (PNPLA3) variant p.lle148Met is associated with early liver injury: analysis of a German pediatric cohort. Gastroenterol Res Pract 2015;2015:1-6.
131 Krawczyk M, Bantel H, Rau M, et al. Could inherited predisposition drive non-obese fatty liver disease? Results from German tertiary referral centers. J Hum Genet 2018;63:621-6

132 Kozlitina J, Smagris E, Stender S, et al. Exome-wide association study identifies a TM6SF2 variant that confers susceptibility to nonalcoholic fatty liver disease. Nat Genet 2014:46:352-6

133 Krawczyk M, Rau M, Schattenberg JM, et al. Combined effects of the PNPLA3 rs738409, TM6SF2 rs58542926, and MBOAT7 rs641738 variants on NAFLD severity: a multicenter biopsy-based study. J Lipid Res 2017;58:247-55.

134 Kozlitina J. Genetic risk factors and disease modifiers of nonalcoholic steatohepatitis. Gastroenterol Clin North Am 2020:49:25-44.

135 Anstee QM, Darlay R, Cockell S. Epos Consortium Investigators. genome-wide association study of non-alcoholic fatty liver and steatohepatitis in a histologically characterised cohort. J Hepatol. In Press 2020

136 Krawczyk M, Liebe R, Lammert F. Toward genetic prediction of nonalcoholic fatty live disease trajectories: PNPLA3 and beyond. Gastroenterology 2020;158:1865-80.

137 Krawczyk M, Stokes CS, Romeo S, et al. Hcc and liver disease risks in homozygous PNPLA3 p.I148M carriers approach monogenic inheritance.. J Hepatol 2015;62:980-1.

138 Anstee QM, Liu Y-L, Day CP, et al. Reply to: HCC and liver disease risk in homozygous PNPLA3 p.I148M carriers approach monogenic inheritance. J Hepatol 2015;62:982-3

139 Geier A, Boursier J. Non-invasive diagnosis of patients with 'at-risk' NAFLD : only fibrosis counts? Gut 2020:69:1164-5.

140 Angulo P, Hui JM, Marchesini G, et al. The NAFLD fibrosis score: a noninvasive system that identifies liver fibrosis in patients with NAFLD. Hepatology 2007;45:846-54

141 McPherson S, Stewart SF, Henderson E, et al. Simple non-invasive fibrosis scoring systems can reliably exclude advanced fibrosis in patients with non-alcoholic fatty liver disease. Gut 2010;59:1265-9.

142 Ratziu V, Massard J, Charlotte F, et al. Diagnostic value of biochemical markers (FibroTest-FibroSURE) for the prediction of liver fibrosis in patients with nonalcoholic fatty liver disease. BMC Gastroenterol 2006;6:6.

143 Guha IN, Parkes J, Roderick P, et al. Noninvasive markers of fibrosis in nonalcoholic fatty liver disease: validating the European liver fibrosis panel and exploring simple markers. Hepatology 2008;47:455-60.

144 Yoneda M, Yoneda M, Yoneda M, et al. Transient elastography in patients with nonalcoholic fatty liver disease (NAFLD). Gut 2007;56:1330-1.

145 Anstee QM, Lawitz EJ, Alkhouri N, et al. Noninvasive tests accurately identify advanced fibrosis due to NASH: baseline data from the stellar trials. Hepatology 2019;70:1521-30.

146 Boursier J, Guillaume M, Leroy V, et al. New sequential combinations of non-invasive fibrosis tests provide an accurate diagnosis of advanced fibrosis in NAFLD. J Hepatol 2019:71:389-96.

147 Angulo P, Bugianesi E, Bjornsson ES, et al. Simple noninvasive systems predict longterm outcomes of patients with nonalcoholic fatty liver disease. Gastroenterology 2013;145:782-9

148 Boursier J, Vergniol J, Guillet A, et al. Diagnostic accuracy and prognostic significance of blood fibrosis tests and liver stiffness measurement by FibroScan in non-alcoholic fatty liver disease. J Hepato/ 2016:65:570-8.

149 Harrison SA, Ratziu V, Boursier J, et al. A blood-based biomarker panel (NIS4) for non-invasive diagnosis of non-alcoholic steatohepatitis and liver fibrosis: a prospective derivation and global validation study. Lancet Gastroenterol Hepato 2020;5:970-85

150 Forlano R, Mullish BH, Giannakeas N, et al. High-Throughput, machine Learning Based quantification of steatosis, inflammation, ballooning, and fibrosis in biopsies from patients with nonalcoholic fatty liver disease. Clin Gastroenterol Hepatol. In Press 2020;18:2081-90

151 Liu F, Goh GB-B, Tiniakos D, et al. qFIBS: an automated technique for quantitative evaluation of fibrosis, inflammation, ballooning, and steatosis in patients with nonalcoholic steatohepatitis. Hepatology 2020;71:1953-66.

152 Diehl AM. Lessons from animal models of NASH. Hepatol Res 2005;33:138-44.

153 Jahn D, Kircher S, Hermanns HM, et al. Animal models of NAFLD from a hepatologist's point of view. Biochim Biophys Acta Mol Basis Dis 2019:1865:943-53.

154 Younossi ZM, Blissett D, Blissett R, et al. The economic and clinical burden of nonalcoholic fatty liver disease in the United States and Europe. Hepatology 2016:64:1577-86.

155 Estes C, Anstee QM, Arias-Loste MT, et al. Modeling NAFLD disease burden in China, France, Germany, Italy, Japan, Spain, United Kingdom, and United States for the period 2016-2030. J Hepatol 2018;69:896-904.

156 Younossi ZM, Ratziu V, Loomba R, et al. Obeticholic acid for the treatment of nonalcoholic steatohepatitis: interim analysis from a multicentre, randomised, placebocontrolled phase 3 trial. Lancet 2019;394:2184-96.

157 Arterburn DE, Telem DA, Kushner RF, et al. Benefits and risks of bariatric surgery in adults: a review. JAMA 2020;324:879-87.

158 Miele L, Forgione A, La Torre G, et al. Serum levels of hyaluronic acid and tissue metalloproteinase inhibitor- 1 combined with age predict the presence of 
nonalcoholic steatohepatitis in a pilot cohort of subjects with nonalcoholic fatty liver disease. Trans/ Res 2009;154:194-201.

159 Santos VND, Leite-Mór MMB, Kondo M, et al. Serum laminin, type IV collagen and hyaluronan as fibrosis markers in non-alcoholic fatty liver disease. Braz I Med Biol Res 2005;38:747-53.

160 Kumagai E, Mano Y, Yoshio S, et al. Serum YKL-40 as a marker of liver fibrosis in patients with non-alcoholic fatty liver disease. Sci Rep 2016;6:35282.

161 Boyle M, Tiniakos D, Schattenberg JM, et al. Performance of the pro-C3 collagen neoepitope biomarker in non-alcoholic fatty liver disease. JHEP Rep 2019;1:188-98.

162 Yilmaz Y, Eren F. Serum biomarkers of fibrosis and extracellular matrix remodeling in patients with nonalcoholic fatty liver disease: association with liver histology. Eur J Gastroenterol Hepatol 2019;31:43-6.

163 Hasegawa T, Yoneda M, Nakamura K, et al. Plasma transforming growth factor-beta1 level and efficacy of alpha-tocopherol in patients with non-alcoholic steatohepatitis: a pilot study. Aliment Pharmacol Ther 2001;15:1667-72.

164 Yang HR, Kim HR, Kim MJ, et al. Noninvasive parameters and hepatic fibrosis scores in children with nonalcoholic fatty liver disease. World I Gastroenterol 2012;18:1525-30.

165 Peleg N, Issachar A, Sneh-Arbib O, et al. Ast to platelet ratio index and fibrosis 4 calculator scores for non-invasive assessment of hepatic fibrosis in patients with non-alcoholic fatty liver disease. Dig Liver Dis 2017;49:1133-8.

166 Feldstein AE, Wieckowska A, Lopez AR, et al. Cytokeratin-18 fragment levels as noninvasive biomarkers for nonalcoholic steatohepatitis: a multicenter validation study. Hepatology 2009;50:1072-8.

167 Huang Y, Adams LA, Joseph J, et al. The ability of Hepascore to predict liver fibrosis in chronic liver disease: a meta-analysis. Liver Int 2017:37:121-31.
168 Abdelmalek MF, Diehl AM, Guy CD. Serum-Based biomarker accurately stratifies hepatic fibrosis in patients with nonalcoholic steatohepatitis. Hepatology 2017;66:55a-6.

169 Aykut UE, Akyuz U, Yesil A, et al. A comparison of FibroMeterTM NAFLD score, NAFLD fibrosis score, and transient elastography as noninvasive diagnostic tools for hepatic fibrosis in patients with biopsy-proven non-alcoholic fatty liver disease. Scand I Gastroenterol 2014;49:1343-8.

170 Martínez SM, Crespo G, Navasa M, et al. Noninvasive assessment of liver fibrosis. Hepatology 2011;53:325-35.

171 Ratziu V, Giral P, Charlotte F, et al. Liver fibrosis in overweight patients. Gastroenterology 2000;118:1117-23.

172 Harrison SA, Oliver D, Arnold HL, et al. Development and validation of a simple NAFLD clinical scoring system for identifying patients without advanced disease. Gut 2008:57:1441-7.

173 Boursier J, Anty R, Vonghia L, et al. Screening for therapeutic trials and treatment indication in clinical practice: MACK-3, a new blood test for the diagnosis of fibrotic NASH. Aliment Pharmacol Ther 2018;47:1387-96.

174 Boursier J, de Ledinghen V, Leroy V, et al. A stepwise algorithm using an at-a-glance first-line test for the non-invasive diagnosis of advanced liver fibrosis and cirrhosis. $J$ Hepatol 2017:66:1158-65.

175 Ampuero J, Pais R, Aller R, et al. Development and validation of Hepamet fibrosis scoring System-A simple, noninvasive test to identify patients with nonalcoholic fatty liver disease with advanced fibrosis. Clin Gastroenterol Hepatol 2020;18:216-25.

176 Newsome PN, Sasso M, Deeks JJ, et al. FibroScan-AST (fast) score for the noninvasive identification of patients with non-alcoholic steatohepatitis with significant activity and fibrosis: a prospective derivation and global validation study. Lancet Gastroenterol Hepatol 2020:5:362-73. 